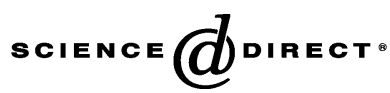

Economics Letters 85 (2004) $157-162$ economics

letters

www.elsevier.com/locate/econbase

\title{
Do causes of environmental problems affect Hicksian equivalent surplus? Evidence from the field
}

\author{
Erwin H. Bulte ${ }^{\mathrm{a}}$, Shelby Gerking ${ }^{\mathrm{b}}$, John A. List ${ }^{\mathrm{c}, *}$, Aart de Zeeuw ${ }^{\mathrm{a}}$

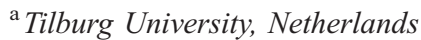 \\ ${ }^{\mathrm{b}}$ University of Central Florida, USA \\ ${ }^{\mathrm{c}}$ AREC and Department of Economics, University of Maryland and NBER, 2200 Symons Hall, College Park, \\ MD 20742-5535, USA
}

Received 23 October 2003; received in revised form 7 January 2004; accepted 3 February 2004

Available online 24 June 2004

\begin{abstract}
Measuring preferences via stated methods remains the only technique to obtain the total economic value of a non-marketed good or service. This study examines if alternative causes of an environmental problem affect individual statements of compensation demanded. Making use of a unique sample drawn from the Netherlands, we find that Hicksian equivalent surplus (ES) is not significantly affected by causes of environmental harm. While our finding that agents only care about outcomes, rather than causes, is consonant with standard applications of utility theory, it is at odds with some recent experimental findings measuring the effects of cause on Hicksian compensating surplus (CS).
\end{abstract}

(C) 2004 Elsevier B.V. All rights reserved.

Keywords: Field experiment; Non-market valuation

JEL classification: C93; Q28

\section{Introduction}

One hallmark of public policy decision-making around the globe is a comparison of the costs and benefits of proposed policies. Indeed, in the US, the Office of Management and Budget recently endorsed the importance of benefit-cost analysis in its revision of the Guidelines for the Conduct of Regulatory Analysis, which must be followed by the various federal agencies proposing new regulation. While stated

* Corresponding author. Tel.: +1-301-405-1288; fax: +1-301-314-9091.

E-mail address: jlist@arec.umd.edu (J.A. List).

URL: http://www.arec.umd.edu/jlist/. 
preference methods are specifically endorsed as an appropriate tool to measure the monetary value of a change in the amount of non-marketed goods and services (i.e., lack of species diversity), the guidelines are mute on whether the process by which these goods are acquired (i.e., the cause of species extinction) influences individual valuation. This approach is certainly consistent with standard economic theory, but it is at odds with recent insights suggesting that people not only care about outcomes, but also about causes.

Various authors (e.g., Kahneman et al., 1993; Kahneman and Ritov, 1994; DeKay and McClelland, 1996; Bulte et al., 2003) use Hicksian compensating surplus data (CS hereafter) to evaluate whether stated willingness to pay (WTP) is affected by the cause of the threat. A common finding is that causes indeed do matter and, more specifically, that people are WTP more to undo harm caused by humans (as opposed to nature). One plausible explanation for this finding is the so-called "outrage effect."

Herein, we evaluate whether a similar effect exists in the context of a willingness to accept (WTA) study measuring equivalent surplus (ES hereafter). Prior evidence on this issue provides ambiguous results. Consistent with the CS results mentioned above, Baron and Ritov (1993) find that respondents demand higher compensation for human-caused injury than for similar injuries caused by 'nature.' This may be due to moral implications driving up WTA. This argument is consistent with Boyce et al. (1992) and Irwin (1994), who find that WTA is more responsive to the mediating role of morality than WTP. In a more recent paper, however, Walker et al. (1999) find that WTA values do not differ across causes. In light of the evidence suggesting that WTP does differ across causes (also documented by Walker et al.), this gives rise to a tantalizing question: Does the WTA-WTP disparity apply to just the magnitudes of responses, or are there qualitative differences between WTA and WTP responses as well? In other words, do WTA and WTP values vary in their size only, or do they respond differently to changes in the context?

In this study, we extend this line of research by examining ES values from a large field experiment. Following the empirical implementation of Bulte et al. (2003), we examine WTA statements of value from 433 questionnaires administered to a panel of Dutch citizens to evaluate whether WTA values to protect a locally threatened species (seals in the Netherlands) are affected by the cause of the threat. We report two major insights. First, the cause of the threat has an insignificant influence on ES. This result is inconsistent with previous data from the same panel measuring the effects of cause on CS. Second, upon combining the CS and ES results, we find that the WTA-WTP disparity is cause-dependent, and greater for natural causes than for human causes - a finding opposite to that reported by Walker et al. (1999).

\section{Data and experimental design}

Data were obtained from a survey of participants in the CentERdata Panel, which consists of more than 2000 households in the Netherlands. Panel members are selected to be representative of the Dutch population. Panelists receive a computer from CentER, Tilburg University, so that they can retrieve and return questionnaires electronically. To ensure a good response rate, before panelists are selected, they are interviewed to investigate their commitment to completing questionnaires to be sent each week. In practice, when given the chance, a large majority of households agree to be part of the CentERdata Panel, ensuring demographic representativeness of our sample. ${ }^{1}$

Following Bulte et al. (2003), our analysis focused on the seal population in the Waddenzee (an estuary in the North of the Netherlands), which reached a low point of about 300 animals in the 1970s.

\footnotetext{
${ }^{1}$ Additional information regarding the panel is available at http://www.centerdata.nl.
} 
Currently, the number of animals has recovered to some 2000 seals, but that number is still much lower than the 18,000 seals that lived in the Waddenzee in the beginning of last century. The seal population is threatened by three possible and distinct developments. First, new diseases (especially certain viruses) have taken a severe toll on the population in the past and continue to pose a serious threat. Second, climate change and the associated rise of the sea level might trigger the disappearance of the seal's breeding grounds. Third, commercial oil and gas drilling may have the same effect, not because the sea level rises, but because the land level falls. The threat from viruses represents the case in which the seal population may be harmed by natural causes for which no societal group is responsible, whereas with oil and gas drilling, actions taken by a comparatively small group of people for private gain contribute directly to the species hardship. Climate change represents an intermediate situation in which virtually everyone is to some extent responsible for the problem.

In the survey, each member of the panel was randomly assigned to one of three groups of equal size. After a brief introduction (common to all groups), in which attention was directed to the declining seal population, each group was presented a script in which one of the three types of threats was highlighted along with a plausible mitigation measure. These scripts, labelled virus, climate change, and oil and gas drilling, are shown below in translation to English from Dutch.

1. Virus: A number of factors continues to threaten the seal population. One important threat is a new virus that undermines the species' resistance to various diseases. The origins of the virus are unknown, but it is regarded as a "natural enemy" of the seal population. The spreading of the virus is a natural process, independent of human actions. It is possible that, without any preventive actions, the seal population in "de Waddenzee" falls by some 50\%. An effective preventive measure would be a vaccination program.

2. Climate change: A number of factors continues to threaten the seal population. One important threat is climate change, mainly caused by burning of fossil fuels. Climate change (or the greenhouse effect) is a global problem because all people using fossil fuels are responsible for the emissions of carbon dioxide in the atmosphere (and not simply people in the Netherlands). An important risk of climate change and the associated rise of the sea level is that breeding grounds will be submerged for longer periods. This will negatively impact on the ability of female seals to deliver and feed young seals. It is possible that, without any preventive actions, the seal population in "de Waddenzee" falls by some $50 \%$. An effective preventive measure would be elevating the existing sand banks by adding sand to them.

3. Oil and gas drilling: A number of factors continues to threaten the seal population. One important threat is drilling for oil and gas in "de Waddenzee." An important risk of gas exploitation is that the land level will fall so that breeding grounds will be submerged for longer periods. This will negatively impact on the ability of female seals to deliver and feed young seals. It is possible that, without any preventive actions, the seal population in "de Waddenzee" falls by some $50 \%$. An effective preventive measure would be elevating the existing sand banks by adding sand to them.

Respondents in each group were then asked to value conservation measures (vaccinations or elevating sand banks, depending on treatment type) to protect the seal population from further harm. In each case, respondents were asked one referendum-type valuation question.

Willingness To Accept: Assume that no special measures are taken to protect the seal population from the above-mentioned threat. Further, assume that the government tries to compensate the Dutch people 
Table 1

Experimental design and raw data summary

\begin{tabular}{lll}
\hline Subject type & Number of subjects & WTA, no. yes (\% yes) \\
\hline Natural (virus) & Dfl $10 ; n=44$ & $9(20.4 \%)$ \\
& Dfl $40 ; n=29$ & $3(10.3 \%)$ \\
& Dfl $80 ; n=31$ & $3(9.7 \%)$ \\
& Dfl $120 ; n=42$ & $6(14.3 \%)$ \\
& Overall; $n=146$ & Overall; $n=21(14.4 \%)$ \\
Society (climate change) & Dfl $10 ; n=36$ & $3(8.3 \%)$ \\
& Dfl $40 ; n=32$ & $1(3.1 \%)$ \\
& Dfl $80 ; n=37$ & $2(5.4 \%)$ \\
Firm (gas drilling) & Dfl $120 ; n=45$ & $9(20 \%)$ \\
& Overall; $n=150$ & Overall; $n=15(10.0 \%)$ \\
& Dfl $10 ; n=40$ & $8(20.0 \%)$ \\
& Dfl $40 ; n=28$ & $0(0 \%)$ \\
& Dfl $80 ; n=33$ & $4(12.1 \%)$ \\
\hline
\end{tabular}

Each cell represents four unique treatments. For example, "Dfl 10" in row 1, column 1 denotes that one treatment had 44 subjects answering a dichotomous choice question on whether they would accept Dfl 10.

for the resulting loss of "nature." If the government offers to pay you a one-time amount of Dfl $X$, would you feel fully compensated for the reduction in the seal population?

$$
\text { "yes" }
$$

Within each of the three experimental cells, respondents were randomly confronted with bid levels drawn from the set (fl 10, 40, 80, 120, where fl $2.2 \approx 1 \approx$ US $\$ 1$ ).

The final sample included 433 panelists, giving a response rate of $75 \%$. We should note that empirical results are qualitatively similar if we exclude data (86 sample points) from participants who provided evidence that they "protested" the entire valuation question. This information was gathered in a post-survey questionnaire. Column 1 in Table 1 provides a summary of the number of respondents in each treatment cell and can be read as follows: In the natural (virus) treatment, 44

Table 2

Sample characteristics

\begin{tabular}{lrr}
\hline Variable & Mean & Standard deviation \\
\hline Respondent is male & 0.55 & 0.50 \\
Respondent's years of age & 46.51 & 14.41 \\
Respondent has only primary education & 0.04 & 0.21 \\
Respondent has secondary education & 0.36 & 0.48 \\
Respondent has vocational training & 0.48 & 0.50 \\
Respondent has university education & 0.11 & 0.31 \\
Household monthly gross income (in Dutch guilders) & 81,450 & 3203 \\
Number of children in respondent's household & 0.82 & 1.11 \\
Number of household members & 2.59 & 1.32 \\
Fraction of respondents with partner in household & 0.76 & 0.43 \\
\hline
\end{tabular}


subjects were asked if they would feel fully compensated for the reduction in the seal population if they received $\mathrm{fl} 10 .^{2}$ Before proceeding to a discussion of the results, we should note that our randomization procedure appeared to work effectively, as respondents across the various treatments were similar in gender, age, gross income, and family size. Table 2 provides the overall means and standard deviations of the various variables.

\section{Analysis of the data}

Our analysis of the field data rests on comparisons of the proportion of respondents across treatments that stated they would accept the amount presented for the resulting loss of seals. These comparisons, presented in the second column of Table 1, provide insights into both treatment effects and the nature of preference structures. Making $F(\bullet)$ the population distribution of acceptances, our series of main null hypotheses take the form $H_{\mathrm{o}}: F\left(T_{i}, \mathrm{fl} Z\right)=F\left(T_{j}, \mathrm{fl} Z\right)$, where $i, j$ are treatment indicators for nature, society, and firm; fl $Z$ represents the offer level, therefore, fl $Z=10,40,80,120$. In this respect, there are 12 distinct tests of treatment effects.

Our first result is that, concerning treatment effects, we can never reject the homogeneity null at conventional significance levels - WTA values do not differ across causes. For example, considering the fl 10 cells, we find that 9 of $44(20.4 \%)$ respondents in the virus treatment accept the fl 10, which is not statistically different from the 3 of 36 ( 8 of 40) respondents who accepted fl 10 in the society (firm) treatment using a test of proportions: $z=1.51(z=0.05)$. As a sensitivity analysis, we also consider (i) use of aggregate statistical tests, ${ }^{3}$ (ii) pooling the fl 10 and fl 40 (fl 80 and fl 120) categories and testing for statistical significance across environmental cause, and (iii) examining whether the overall proportions vary across environmental cause (i.e., whether $14.4 \%$ (natural) is different from $10.0 \%$ (society)). Across all of these testing procedures, we can only make one rejection of homogeneity at conventional significance levels: the pooled fl 10 and fl 40 data from the virus treatment are significantly different from the pooled fl 10 and fl 40 data from the climate change treatment $(z=1.97)$. We thus conclude that in our data there is not strong evidence that the cause of the environmental harm significantly influences ES. This finding is at odds with most recent research concerning CS and ES as summarized in Section 1, but is consistent with Walker et al. Since our sample size is larger (Walker reports the results of two experiments with 72 and 58 respondents), our results provide an important verification of their work. ${ }^{4}$

\footnotetext{
${ }^{2}$ Future studies should attempt to experiment with larger WTA values (and larger sample sizes), as our sample had many respondents not feeling fully compensated with even our largest (fl120) figure. The corresponding fact that a small increase in the fraction of "yes" votes in any given cell could generate inferential differences highlights the importance of using even larger samples for such an exercise.

3 Recall that the sum of independent normal variables has a normal distribution with mean equal to the sum of the means, and variance equal to the sum of the variances. Consider the nature versus society comparisons. In the various treatments: $f l 10$, $z=1.51 ; f l 40, z=1.14 ; f l 80, z=0.67 ; f l 120, z=-0.70$. Since the four $z$-statistics are independent and standard-normal, their sum should have mean 0 and variance 4 under the null hypothesis that the treatment has no effect. Our aggregate $z$-statistic is therefore the sum of the four $z$-statistics, divided by the square root of 4 , or $z=0.66$ in this case.

4 We have also estimated a linear WTA regression model controlling for respondent characteristics and treatment type and found qualitatively similar insights. These results are available upon request.
} 
Our second major result follows directly from the first result. A previous study, using the same panel and case study, found that people are willing to pay significantly more to correct problems caused by humans than by nature (Bulte et al., 2003). Since WTA values are not similarly affected, the WTA-WTP disparity does not appear to be independent of context. Since WTP is greater to undo harm caused by humans, the WTA-WTP disparity is smaller for human causes than for natural ones. ${ }^{5}$ This finding lends insights into the value disparity that may be important.

\section{Epilogue}

For a technique with such clear importance in policy circles, it is puzzling that many loose ends remain within the non-market valuation literature. In this study, we contribute to the literature by examining Hicksian equivalent surplus across various causes of environmental damage. Using field data gathered from 433 respondents, we report two major insights. Perhaps most importantly, the nature of the cause is not found to influence equivalent surplus. This finding is consistent with standard applications of utility theory and the current manner in which policymakers apply benefit-cost analysis.

\section{Acknowledgements}

Thanks to an anonymous reviewer for helpful comments. Glenn Harrison and Laura Taylor also provided useful discussion. The University of Central Florida and CentERdata provided research funds. Any errors or omissions remain our responsibility.

\section{References}

Baron, J., Ritov, I., 1993. Intuitions about penalties and compensation in the context of tort law. Journal of Risk and Uncertainty 7, 17-33.

Boyce, R., Brown, T., McClelland, G., Peterson, G., Schulze, W., 1992. An experimental examination of intrinsic values as a source of the WTA-WTP disparity. American Economic Review 82, 1366-1373.

Bulte, E.H., Gerking, S.D., List, J.A., de Zeeuw, A.J., 2003. The Effect of Varying the Causes of Environmental Problems on Stated Values: Evidence from a Field Study. Tilburg University, Department of Economics, Discussion Paper.

DeKay, M., McClelland, G., 1996. Probability and utility components of endangered species preservation programs. Journal of Experimental Psychology. Applied 2, 60-83.

Irwin, J., 1994. Buying/selling price preference reversals: preference for environmental changes in buying versus selling modes. Organizational Behavior and Human Decision Processes 60, 431-457.

Kahneman, D., Ritov, I., 1994. Determinants of stated willingness to pay for public goods: a study in the headline method. Journal of Risk and Uncertainty 9, 5-38.

Kahneman, D., Ritov, I., Jacowitz, K.E., Grant, P., 1993. Stated willingness to pay for public goods: a psychological perspective. Psychological Science 4, 310-315.

List, J.A., 2003. Does market experience eliminate market anomalies? Quarterly Journal of Economics 118 (1), $41-71$.

List, J.A., 2004. Neoclassical theory versus prospect theory: evidence from the marketplace 72(2), 615-625.

Walker, M.O., Morera, J.V., Orland, B., 1999. Disparate WTA-WTP disparities: the influence of human versus natural causes. Journal of Behavioral Decision Making 12, 219-232.

\footnotetext{
5 We point the interested reader to List $(2003,2004)$ for a broader discussion of context and the WTA-WTP value disparity.
} 